\title{
Early vs. Delayed Hormonal Treatment in Locally Advanced or Asymptomatic Metastatic Prostatic Cancer Patient Dilemma: A Review
}

\author{
Domenico Prezioso*, Fabrizio lacono, Giuseppe Romeo, Antonio Ruffo, Nicola Russo and Ester Illiano
}

Department of Urology, University Federico II of Naples, Italy

\begin{abstract}
Introduction: Hormonal therapy for prostate cancer has been used for more than 60 years in patient. Whether immediate or deferred hormonal treatment is best for patients with locally advanced prostate cancer (LAPC) and/or or asymptomatic metastasis who are not suitable for curative local treatment of prostate cancer has been debated since its introduction. The objective of this work is to compare the effectiveness of hormonal treatment as an early or as a deferred intervention for patients with (LAPC) and/or asymptomatic metastasis.
\end{abstract}

Materials and methods: Systematic review and meta-analysis of trials published during 1950 to 2011 .

Results: We retrieved 22 articles for detailed review, of which 8 met inclusion criteria. The Veterans Administration Cooperative Urological Research Group (VACURG) suggested that delaying hormonal therapy did not compromise overall survival and that many of the patients died of causes other than prostate cancer. In the European Organization for Research and Treatment of Cancer (EORTC) 30846 trial the median survival for delayed endocrine treatment was $6.1 \mathrm{yr}$ and for immediate treatment $7.6 \mathrm{yr}$, the HR for survival on delayed vs immediate treatment was 1.23 $(95 \% \mathrm{Cl} 0.88$ to 1.71$)$, indicating a $23 \%$ non significant trend in favor of early treatment. In protocol EORTC 30891 the immediate androgen deprivation resulted in a modest but statistically significant increase in overall survival but no significant difference in prostate cancer mortality or symptom-free survival. The protocol SAKK 08/88 showed for elderly, asymptomatic patients not undergoing curative local treatment, the lack of any major advantage of immediate compared with deferred hormonal treatment regarding quality of life or overall survival.

Conclusions: The early intervention with hormonal treatment for patients with LAPC provides important reductions in all-cause mortality, prostate cancer-specific mortality, overall progression, and distant progression compared with deferring their use until standard care has failed to halt the disease.

Keywords: Locally advanced prostate cancer; Early hormonal treatment; Delayed hormonal treatment; Castration-resistant prostate cancer

Abbreviations: APC: Advanced Prostate Cancer; BMD: Bone Mineral Density; BMI: Body Mass Index; CAB: Combined Androgen Blockade; CI: Confidence Interval; CPA: Cyproterone Acetate; CRPC: Castration-Resistant Prostate Cancer; DES: Diethylstilbestrol; DET: Delayed Endocrine Treatment; EET: Early Endocrine Treatment; EORTC: European Organisation for Research and Treatment of Cancer; EPC: Early Prostate Cancer; HR: Hazard Ratio; LAPC: Locally Advanced Prostate Cancer; LHRH: Luteinising HormoneReleasing Hormone; MAB: Maximum Androgen Blockade; MRC: Medical Research Council; NSAA: Nonsteroidal Anti-Androgen; OS: Overall Survival; PFS: Progression-Free Survival Benefit; PSA: Prostate-Specific Antigen; RP: Radical Prostatectomy; RR: Relative Risk; RTC: Randomised Controlled Clinical Trial; SEER: Surveillance Epidemiology and End Results; SWOG: South West Oncology Group; VACURG: Veterans Administration Cooperative Urological Research Group

\section{Introduction}

Prostate cancer is the most commonly diagnosed cancer for men living in developed countries (other than non- melanoma skin cancer). According to Surveillance Epidemiology and End Results (SEER) [1], it is estimated that 241,740 men will be diagnosed with and 28,170 men will die of cancer of the prostate in 2012. From 2005-2009, the median age at death for cancer of the prostate was 80 years of age. Approximately $0.0 \%$ died under age 20;0.0\% between 20 and 34; $0.1 \%$ between 35 and $44 ; 1.5 \%$ between 45 and $54 ; 8.0 \%$ between 55 and $64 ; 19.8 \%$ between 65 and $74 ; 38.6 \%$ between 75 and 84 ; and $32.0 \%$
$85+$ years of age. The age-adjusted death rate was 23.6 per 100,000 men per year. In 1941, the pioneering work of Huggins and Hodges provided clear evidence that patients with symptomatic metastatic disease benefit from some form of testosterone suppression [2,3]. Yet, despite over 6 decades of research and clinical experience, few areas of medicine generate as much uncertainty and debate as the hormonal manipulation of advanced prostate cancer. A key area of controversy is the relative utility of surgical and/or medical therapies. Bilateral surgical orchiectomy, estrogens, and luteinizing hormone-releasing hormone (LHRH) agonists all provide patients with castrate levels of testosterone. However, in many patients, the small amounts of androgens released by the adrenal glands continue to support tumor growth $[3,4]$. High-risk surgical removal of the adrenal glands has been replaced by steroidal and nonsteroidal antiandrogens, which block the activity of adrenal androgens. Combining an antiandrogen with medical or surgical castration is considered combined androgen blockade $(\mathrm{CAB})$ and results in total androgen suppression. However,

*Corresponding author: Domenico Prezioso, Department of Urology, University Federico II of Naples, Via S. Pansini, 5 - 80131 Naples, Italy, Tel: +390817462606; E-mail: dprezioso@libero.it

Received January 22, 2013; Accepted February 26, 2013; Published March 05 , 2013

Citation: Prezioso D, lacono F, Romeo G, Ruffo A, Russo N, et al. (2013) Early vs. Delayed Hormonal Treatment in Locally Advanced or Asymptomatic Metastatic Prostatic Cancer Patient Dilemma: A Review. J Steroids Hormon Sci S5: 001. doi:10.4172/2157-7536.S5-001

Copyright: (c) 2013 Prezioso D, et al. This is an open-access article distributed under the terms of the Creative Commons Attribution License, which permits unrestricted use, distribution, and reproduction in any medium, provided the original author and source are credited. 
the debate continues regarding the safety, efficacy, and long-term utility of this approach. Since that time, great controversy has arisen regarding the optimal timing for the initiation of hormonal therapy. Today, because of prostate-specific antigen (PSA) screening and early detection, patients are diagnosed much earlier than in the past, resulting in a long natural history of disease before the development of metastasis or death. Men with localised or locally advanced prostate cancer and a life expectancy of 10 yrs are typically offered primary therapy of curative intent, that is, radical prostatectomy, external beam radiotherapy or brachytherapy [5]. However, a significant proportion of patients undergoing these therapies experience disease progression (clinical and/or biochemical) and may ultimately die from their prostate cancer [6-9]. Indeed, among men with a biochemical failure after radical prostatectomy, the median time to developing metastasis is 8 years and the median time to death an additional 5 years [10]. Although prostate cancer usually progresses slowly, a patient's prognosis and subsequent treatment depends heavily on the grade of the tumour at diagnosis [11]. A 10-year prostate cancer-specific survival of $>90 \%$ was reported in men with early, low-grade tumours, and of $>75 \%$ among those with intermediate-grade tumours [12]. As would be expected, there is a significant decline in 10-year prostate cancer-specific survival. Then why delay hormonal therapy in PC? At the time of diagnosis even advanced PC is often asymptomatic. Patients are therefore confronted with the adverse effects of hormonal therapy as the only 'symptom' of their cancer. Clearly, there is a need to achieve a balance between the impact of hormonal therapy on the general well-being and quality of life against the potential clinical benefit. Infact, hormonal therapy can affect quality of life [13]. Prostate cancer progression can have a serious impact on patients' quality of life $[14,15]$. Advancing disease may be associated with debilitating disease-related complications, such as painful bone metastases and urinary tract obstruction $[16,17]$, and can cause considerable emotional distress [18]. Therefore, within this context, when is the best time to begin hormonal therapy, and is that timing the same for all men? This review will analyse data from randomized controlled trials of early versus delayed hormonal therapy (early versus delayed) in locally advanced or asymptomatic metastatic prostate cancer.

\section{Materials and Methods}

\section{Evidence acquisition}

Literature search: The CENTRAL and MEDLINE databases were searched for relevant abstracts and papers; all searching was completed in December 2012. We searched Medline using the following terms: 'prostate cancer' (or 'locally advanced prostate cancer'); surgery (including 'orchiectomy' or 'castration'); active surveillance; hormonal therapy, including antiandrogens or the LHRH agonists; early hormonal therapy; delayed hormonal therapy. Bibliographies of retrieved trials and review articles also were examined.

Selection criteria: A trial was eligible for inclusion if it met the following criteria: 1) it was composed of community dwelling participants aged $\leq 80 \mathrm{yr} ; 2$ ) a study design that was randomized and controlled; 3 ) it compared early versus delayed hormonal therapy in locally advanced and asymptomatic metastatic disease; 4) it compared hormonal therapy (i.e. LHRH agonist or NSAA) with deferred treatment (i.e. hormonal therapy after watchful waiting) in patients with locally advanced prostate cancer (LAPC) 5) it had at least a 5 years follow-up; 6) where a randomised controlled clinical trial (RCT) included patients with different treatment of prostate cancer, e.g. (radiotherapy, surgery, hormonal therapy o watchful waiting/active surveillance), only hormonal therapy data were extracted; 7) it was published in English.

Data extraction and outcome measures: Data were extracted in a standardized fashion, including trial characteristics; patient characteristics, median duration of follow-up (e.g. 5, 15 years, etc.); hormonal treatment regimen (e.g. early, delayed); The following trial efficacy outcomes were considered for inclusion in this review: 1) overall mortality; 2) prostate cancer-specific mortality; 3) overall progression;4) local progression; 5) distant progression. Where a RCT included patients with different stages of prostate cancer, e.g. LAPC and APC, only the LAPC data were extracted. If there were multiple publications of the same study, the latest publication was used. If the latest publication did not provide data for all outcomes, then previous publications were used if they contained the missing data.

Assessment of methodologic quality: Studies were assessed for quality of concealment of randomized treatment allocation and were assigned scores from 1 for poorest quality to 3 for best quality.

Statistical analysis: The meta-analyses used the Mantel-Haenszel method (a fixed-effects model); this model was used rather than a random-effects model in the primary analysis, as the weighting favours larger trials in a fixed-effects model, rather than the more equal weighting across all trials used in a random-effects model [19]. The summary effect estimate was calculated as a relative risk (RR) with 95\% CI, as a RR is more easily interpreted than other summary effect estimates such as an odds ratio [20]. Publication bias was assessed by using a regression of normalized effect vs precision, using the method proposed by Egger et al. [21]. For all analyses we used Stats Direct version 2.5.6 [22].

\section{Evidence Synthesis}

\section{Study selection}

We identified 579 citations via our Medline search. After review of titles and abstracts, we retrieved 22 articles for detailed review, of which 8 met inclusion criteria. No additional references identified from bibliographies of retrieved trials and review articles met inclusion criteria.

\section{Trial characteristics}

Eight trials of hormonal treatment of prostate cancer met eligibility criteria and were included in this review. All trials were published in peer-reviewed English-language journals and indicated that they were randomized; all trials used a parallel treatment group design. Treatment duration ranged from 3 years to 13 years (Table 1).

\section{Participant characteristics}

Trial participants were predominately young (range of mean ages: 60-80 yr) (Table 1). Most studies were limited to participants with locally advanced prostate cancer or asymptomatic metastasis to either immediate treatment (orchiectomy or LHRH agonist) or to the same treatment deferred until an indication occurred.

\section{Efficacy Outcomes}

Since the introduction of androgen withdrawal therapy, controversy has existed over its optimal timing. Many have advocated beginning treatment at the time of diagnosis in hopes of delaying disease progression and possibly prolonging survival. Others have argued that survival is not prolonged and the treatment may be deferred until symptoms develop. Early studies by Nesbit and Baum [23] provide 
Citation: Prezioso D, lacono F, Romeo G, Ruffo A, Russo N, et al. (2013) Early vs. Delayed Hormonal Treatment in Locally Advanced or Asymptomatic Metastatic Prostatic Cancer Patient Dilemma: A Review. J Steroids Hormon Sci S5: 001. doi:10.4172/2157-7536.S5-001

Page 3 of 8

\begin{tabular}{|c|c|c|c|c|c|c|}
\hline Trial code & Type of patients & Trial design & N.of patients & Patientage, years & Comparison & Median FU, years \\
\hline MRC & cT2-4, any N & $\begin{array}{l}\text { Open, } \\
\text { randomized }\end{array}$ & 500 & 500 & $\begin{array}{l}\text { WW vs. GOS AA } \\
\text { (or BOx) until progression (M0 } \\
\text { patients only) }\end{array}$ & $<11$ \\
\hline $\begin{array}{l}\text { EORTC } \\
30846\end{array}$ & $\mathrm{pN} 1-3$ & $\begin{array}{l}\text { Open, } \\
\text { randomized }\end{array}$ & 234 & $71(51-58)$ & $\begin{array}{c}\text { RT vs. RT+GOS (starting on day } 1 \\
\text { of RT) for } 3 \text { years CPA oral for } 28 \\
\text { days }\end{array}$ & 8.5 \\
\hline $\begin{array}{l}\text { EORTC } \\
30891\end{array}$ & TO-4 N0-2 MO & $\begin{array}{l}\text { Open, } \\
\text { randomized }\end{array}$ & 985 & $73(52-81)$ & $\begin{array}{l}\text { WWvs.BUSCPAoral for } 14 \text { days } \\
\text { (or subcapsular Ox) until } \\
\text { progression }\end{array}$ & 7.8 \\
\hline \multirow[t]{2}{*}{$\begin{array}{l}\text { EPC } \\
\text { WW } \\
\text { subgroup }\end{array}$} & $\begin{array}{l}\text { Locally advanced:cT3- } \\
\text { 4,any } \mathrm{N} \text { or any } \mathrm{T}, \mathrm{N}+\end{array}$ & $\begin{array}{l}\text { Double-blind } \\
\text { randomized }\end{array}$ & 657 & $67(38-93)$ & BIC vs. placebo & 5.4 \\
\hline & $\begin{array}{l}\text { Localised:cT1-2,N0 or } \\
\qquad \mathrm{Nx}\end{array}$ & $\begin{array}{l}\text { Double-blind } \\
\text { randomized }\end{array}$ & 1627 & $67(38-93)$ & BIC vs. placebo & 5.4 \\
\hline $\begin{array}{l}\text { SAKK } \\
08 / 88\end{array}$ & $\begin{array}{l}\text { T0-4, N0-2, M0-1 } \\
\text { (UICC 1982) }\end{array}$ & $\begin{array}{l}\text { Open, } \\
\text { randomized }\end{array}$ & 197 & $76(56-86)$ & Immediate Ox vs. delayed Ox & $>5$ \\
\hline
\end{tabular}

GOS, goserelin 3.6 mg s.c. every 28 days; FLU, flutamide 250 mg oral three times daily; BIC, bicalutamide 150 mg once daily; BUS, buserelin 6.3 mg; CPA, cyproterone acetate; WW, watchful waiting; AA, antiandrogen; $\mathrm{BOx}$, bilateral orchidectomy

Table 1: Trial characteristics

\begin{tabular}{|c|c|c|c|c|}
\hline \multirow[t]{2}{*}{ Trial code } & \multicolumn{2}{|c|}{ Clinical progression } & \multicolumn{2}{|c|}{ Overall survival } \\
\hline & Progression rate $(\%)$ & HR (p-value) & Mortality rate (\%) & HR ( $p$-value) \\
\hline $\begin{array}{l}\text { MRC trial M0 subgroup } \\
\text { EORTC } 30846\end{array}$ & $\begin{array}{l}38 \text { vs. } 59 \\
\text { Not reported }\end{array}$ & $\begin{array}{l}\text { Not reported }(p<0,001) \\
\text { Not reported }\end{array}$ & $\begin{array}{l}59 \text { vs. } 70 \\
61 \text { vs. } 62\end{array}$ & $\begin{array}{c}\text { Not reported }(p=0,02) \\
1,23(N S)\end{array}$ \\
\hline EPC (1) & 44 vs. 61 & $0,53(p<0,0001)$ & 34 vs. 41 & $0,81(p=0,097)$ \\
\hline EPC (2) & 29 vs. 32 & $0,81(p=0,018)$ & 25 vs. 21 & $1,23(p=0,050)$ \\
\hline SAK 08/88 & Not reported & Not reported & 24 vs. 37 & $0,99(p=0,096)$ \\
\hline EORTC 30891 & Not reported & Not reported & $52.2 \%$ vs. 57 & $1,25(p=0,434)$ \\
\hline
\end{tabular}

HR, Hazard ratio

Table 2: Efficacy outcomes.

evidence to support the immediate treatment of advanced prostate cancer. They compared patients who were treated with orchiectomy, DES, or both and then compared them with untreated historical controls. The treated group showed a 5 -year survival rate of $34 \%$ versus $10 \%$ in the untreated group. The Veterans Administration Cooperative Urological Research Group (VACURG) conducted a consecutive series of 3 major randomized clinical trials comparing various endocrine treatments for newly diagnosed prostate cancer patients. They suggested that delaying hormonal therapy (DES) did not compromise overall survival and that many of the patients died of causes other than prostate cancer [24]. However, a stringent reanalysis of the VACURG data showed that younger patients with high-grade tumors and those with stage $\mathrm{M}+$ disease derive a survival benefit from the early initiation of androgen withdrawal therapy [25]. Recent studies provide convincing clinical evidence supporting the early treatment of advanced prostate cancer, infact there are clear benefits associated with using early hormonal therapy as an alternative to watchful waiting in patients with locally advanced disease (Table 2). For this patient group, who have a high chance of progression, the results from trials of castration therapy [26-28] or a nonsteroidal antiandrogen [29] indicate to me that a watchful waiting approach is not appropriate and that hormonal therapy is best started at, or soon after, diagnosis. A significant clinical benefit in favour of early castration therapy was first demonstrated in a trial conducted by the Medical Research Council (MRC) [26]. Nine hundred and thirty-eight patients with locally advanced or asymptomatic metastatic prostate cancer were randomized either to immediate treatment (orchidectomy or luteinizing hormonereleasing hormone analogue) or to the same treatment deferred until an indication occurred. Follow-up data were returned on 934 patients;
51 deferred patients died from causes other than prostate cancer before treatment was started and 29 died from prostate cancer before treatment could be started. Treatment was commenced for local progression almost as frequently as for metastatic disease. In the delayed treatment arm, the median time to hormonal therapy was only 9 months. Progression from M0 to M1 disease occurred more rapidly in deferred patients ( 38 vs. $59 \%$; $<<0.001$ ). A first analysis demonstrated significant advantages for early vs. deferred castration therapy in improving overall survival (mortality 59 vs. $70 \%$; $=0.02$ ). Of the patients who died, 361 patients died in the deferred arm compared with 328 in the immediate arm $(p=0.02$,$) , where 257$ and 203 were deaths from prostate cancer, respectively ( $\mathrm{p}=0.001$ two-tailed). This difference was seen largely in M0 patients, with 119 and 81 deaths from prostate cancer, respectively ( $<<0.001$ two-tailed). A later analysis (performed after $86 \%$ of the overall trial population had died) found that the treatment difference in overall survival was no longer statistically significant. The reduction in this treatment difference was explained by the emergence of a higher rate of non prostate cancer deaths with early vs. deferred castration therapy [27]. The European Organization for Research and Treatment of Cancer (EORTC) 30846 trial [28] evaluated the effectiveness of 9.6 years of early human treatment patients with lymph node positive cancer without local treatment of the primary tumor. A total of 302 patients with metastatic regional lymph nodes who had not received local treatment for the primary tumor were included in the trial, of whom 234 were randomized to immediate vs. delayed endocrine treatment. Endocrine treatment consisted of $3.6 \mathrm{mg}$ of goserelin given subcutaneously every $4 \mathrm{wk}$ and cyproterone acetate (CPA) $50 \mathrm{mg}$ given orally 3 times per day for the first $4 \mathrm{wk}$ of treatment. Change from DET to endocrine treatment was indicated upon clinical 
progression or, at the investigators discretion upon subjective progression, based on a rise of serum prostate-specific antigen (PSA) or an increase in the $\mathrm{T}$ category or prostatic volume. In this trial at 8.7 year median follow-up, the median survival for delayed endocrine treatment was 6.1 year and for immediate treatment 7.6 year, the HR for survival on delayed vs. immediate treatment was 1.23 (95\% CI 0.88 to 1.71 ), indicating a $23 \%$ nonsignificant trend in favor of early treatment. The 5 -year cumulative incidence of PCa mortality was $28.0 \%$ in the delayed arm and $23.2 \%$ in the immediate treatment arm. Protocol EORTC 30891 in patients with localized prostate cancer not suitable for local curative treatment. They assigned 985 patients with newly diagnosed prostate cancer T0-4 N0-2 $\mathrm{M} 0$ to receive androgen deprivation either immediately $(n=493)$ or on symptomatic disease progression or occurrence of serious complications $(n=492)$. At the time of analysis 257 of 492 patients $(52.2 \%)$ on the immediate and 284 of 493 patients (57.6\%) on the deferred treatment arm had died. In both arms the leading causes of death were prostate cancer (35.7\%) and cardiovascular diseases (34.2\%). The intent to treat analysis failed to prove noninferiority for overall survival, with a median of 6.5 years $(95 \% \mathrm{CI}$, 5.9 to 7.2$)$ on deferred treatment compared with 7.4 years $(95 \% \mathrm{CI}, 6.6$ to 8.5$)$ on immediate treatment $(\mathrm{p}=0.4341)$, corresponding to a mortality hazard ratio of 1.25 (95\% CI, 1.05 to 1.48$)$ that indicates with $95 \%$ confidence a $5 \%$ to $48 \%$ increase of the risk of death on the deferred arm [29]. The comparison of the cumulative incidence of prostate cancer death, based on only 193 events and thus with limited statistical power, showed no significant difference between the treatment arms ( $\mathrm{p}=0.4361$ ): at 5 and 10 years, the difference was $4.2 \%$ (95\% CI, $0.2 \%$ to $8.2 \%$ ) and $1.2 \%$ (95\% CI, $5.9 \%$ to $8.3 \%$ ), respectively. The time from random assignment to the first symptomatic progression was significantly longer for patients on the immediate treatment arm [30]. The Early Prostate Cancer (EPC) [27] programme demonstrated that bicalutamide monotherapy significantly reduces the risk of disease progression in patients with locally advanced disease. Infact a total of 8,113 men with T1b-T4, M0, any $\mathrm{N}+\mathrm{N} 0$ prostate cancer were randomized to bicalutamide $150 \mathrm{mg} /$ day $(4,052)$ or placebo $(4,061)$ in addition to standard care (radical prostatectomy, radiotherapy or watchful waiting). At median 5.4 years of followup (21.6\% progression events) bicalutamide significantly improved PFS (progression-free survival) benefit in the overall population (HR 0.53; $<<0.0001$ ). Among watchful waiting patients survival appeared to be improved with bicalutamide in those with locally advanced disease (HR 0.81; $\mathrm{p}=0.097$ ), whereas survival appeared to be reduced with bicalutamide in those with localized disease (HR 1.23; $\mathrm{p}=0.05$ ). These data suggest that, for patients with localised disease not suitable for primary therapy of curative intent because of age or comorbid- ities, watchful waiting with hormonal therapy deferred until signs of progression may be the best option. This strategy would be consistent with a recent report on the use of active surveillance for patients with low- risk localised disease, with selective delayed intervention being initiated depending on specific disease progression criteria (e.g. rapid PSA progression) [31]. Protocol SAKK 08/88 evaluated the timing of hormonal therapy with immediate or deferred subcapsular orchiectomy to determine whether there is a significant difference in overall survival, symptom-free survival, or incidence of complications. 197 patients with newly diagnosed histologically or cytologically confirmed prostate cancer with or without soft tissue and/or bone metastases who were asymptomatic and without previous treatment, and with a median age of 76 years (range, 56 to 86 years) were randomly assigned to receive either immediate or deferred orchiectomy on symptomatic progression (96 were in the immediate-treatment arm and 92 were in the deferredtreatment arm). The time to onset of pain or ureteric obstruction caused by progressive disease or until new (symptomatic or asymptomatic) metastases were documented was significantly longer in patients undergoing immediate orchiectomy (HR, 0.57; 95\% CI, 0.39 to $0.84 ; \mathrm{p}<0.01$ ), Median time difference is approximately 2.8 years. The time from random assignment to the first appearance of pain, ureteric obstruction, or new bone metastases requiring additional treatment after immediate or deferred orchiectomy did not differ substantially (HR, 1.04; 95\% CI, 0.66 to $1.64 ; \mathrm{p}=0.86$ ). If the time spent with symptoms before treatment in the deferred arm is subtracted, the result remains essentially the same (HR, $1.0 ; 95 \% \mathrm{CI}, 0.64$ to 1.57 ; $\mathrm{p}=0.99$ ). Death as a result of progressive prostate cancer was reported in 23 of 96 patients (24\%) in the immediate- orchiectomy group and in 34 of 92 patients (37\%) in the deferred-orchiectomy group. Overall survival was not significantly different between the two treatment groups (HR, 0.99 ; $95 \%, \mathrm{CI}, 0.74$ to $1.34 ; \mathrm{p}=0.96)$. Median survival time was 5.2 years $(95 \%$ CI, 4.5 to 6.4 years) for the immediate and 4.4 years $(95 \%$ CI, 3.6 to 6.1 years) for the deferred group. Overall pain-free survival (ie, the time to occurrence of symptomatic progressive disease after immediate or deferred orchiectomy) was not significantly different (HR, 1.07; 95\% CI, 0.66 to $1.72 ; \mathrm{p}=0.79$ ) between the treatment arms. Time to progression after immediate or deferred orchiectomy, cancer-specific survival, and pain-free interval were significantly reduced in patients with metastases (HR, 3.87, 2.11, and 4.05 ; 95\% CI, 2.31 to $6.46,1.59$ to 2.79 , and 2.39 to 6.88 , respectively; $\mathrm{p}<0.001)$. Overall survival was significantly lower in patients with metastatic (HR, 1.46, 95\% CI, 1.21 to 1.76 ; $\mathrm{p}<0.001$ ) or node-positive disease (HR, 1.23; 95\% CI, 1.02 to 1.49 ; $\mathrm{p}=0.033$ ) [32].

\section{Adverse Effects of Hormonal Treatment}

Most adverse events of currently used types of endocrine management of PC can be directly related to underlying endocrinological mechanisms. The specific adverse events seen with flutamide and cyproterone acetate were subject to comparison in a randomized study of the EORTC-GU group (protocol 30892). Painful gynecomastia, nausea and diarrhea were more frequently seen with flutamide and occurred at rates of 43,17 , and $23 \%$, respectively and cardiovascular problems were equally distributed between arms. Flutamide toxicity required discontinuation of treatment in $17.9 \%$ as opposed to $7.2 \%$ with cyproterone acetate [28]. LHRH agonists are used in subcutaneously injectable preparations and leads after an initial rise of gonadotropins, to a decrease in LHRH and testosterone. In cases with metastatic disease, especially in symptomatic patients, the initial rise of plasma testosterone can lead to an increase of clinical symptoms and even death (the flare phenomenon) which is usually prevented by an antiandrogen at least during the initial treatment period [32]. Continuous treatment by combining an LHRH agonist and an anti-androgen (total androgen blockade or maximal androgen blockade) is not discussed in this review, which will be limited to the side effects of castration and LHRH monotherapy, the treatment principles most frequently used in early versus delayed regimens. The primary goal of endocrine therapy is to reach castrate levels of plasma testosterone. Castrate levels of plasma testosterone have in the past been defined as ranging from 0.7 to $1.7 \mathrm{nmol} / \mathrm{l}(20-50 \mathrm{ng} / 100 \mathrm{ml})$, but have more recently been redefined as $0.7 \mathrm{nmol} / \mathrm{l}(20 \mathrm{ng} / 100 \mathrm{ml})$ [33]. Tissue androgen levels were subject to much debate; testosterone is the substrate of 5-a-reductases type I and type II. Type II is predominantly located in the prostate and produces 5 -a-dihydrotestosterone (DHT), the most active androgen in prostatic development and function. Remaining DHT levels derived from adrenal androgens can be blocked by anti-androgens. This has resulted in the concept of maximal androgen blockade [34] The most definitive single randomized study is South West Oncology 
Group (SWOG) Intergroup protocol 105 of which Eisenberger et al. [35] reported negative results. Maximal androgen blockade has been rarely used in EET (early endocrine treatment) versus DET (delayed endocrine treatment) trials. The differential side effects of this regimen will therefore not be addressed. Adverse events of ET are related to the sudden and drastic decrease of the production of testosterone and the decreasing plasma testosterone levels. Since castration and LHRH agonists are almost exclusively used in metastatic or regionally extensive PC and survival of patients with such conditions is limited, virtually no knowledge is available concerning side effects occurring with ET of a very long duration, therefore, ET is necessary in men with locally confined disease or a rising PSA after potentially curative management. Libido and sexual potency rapidly decreases after castration in line with the occurrence of hypogonadic testosterone levels. It is unexplained why even with long-term observations, more than $20 \%$ of castrated men remain sexually active and claim normal erectile function [36]. With the use of antiandrogen monotherapy, sexual function decreases more slowly (by about $50 \%$ per year), but eventually reaches a $20 \%$ level [37]. Hot flushes are the most frequent adverse effect of castration and LHRH management occurring in almost $80 \%$ of patients. Radlmaier et al. [38] have elucidated the endocrine mechanism and showed that cyproterone acetate, which is available in Europe but not in the US is an effective treatment. Megestrol acetate, a progestagen with some androgenic activity, has been studied and shown to significantly decrease the frequency of hot flushes [39]. A study by Dawson and McLeod [40] and Daniell [41] have compared the risk of spontaneous fractures in castrated and normal men over a period of 9 years. After this time period, the risk of fractures was $50 \%$ in the castrated and $7 \%$ in the non-castrated group. Several recent studies have shown that bone mineral density (BMD) decreases significantly after castration. However, the same study shows that at 5 years of observation the rate of spontaneous fractures is 19.6 and $12.4 \%$ in men with and without androgen deprivation. A randomized study has revealed that zoledronic acid given at a dosage of $4 \mathrm{mg}$ every 3 months for a period of a year significantly decreased the loss of BMD and symptomatic skeletal adverse events. Pre-existing osteoporosis is a significant risk factor. These men are probably the best candidates for additional treatment with bisphosphonates after castration or with the use of LHRH agonist depots [42]. Serum testosterone levels are positively related to muscle mass and correlate negatively with the body mass index (BMI). The changes include the increase in the total fat mass of the body [43]. Yannucci et al. [44] suggests changes in cholesterol and blood lipid composition with an increase of HbAlc. Keating et al. [45] studied found that with the use of GNRH agonists, the adjusted HRs for diabetes, coronary heart disease, myocardial infarction, and sudden cardiac death were modestly but significantly increased with respect to HR of $1.44,1.16,1.11$, and 1.16. After castration, the risk of developing diabetes was only increased (HRZ1.34). Their long-term persistence with long-term endocrine management in M0 disease might still lead to cardiovascular complications. In this author's view, especially men with cardiovascular risk factors should be monitored carefully. Cognitive and mood changes (declines in visual memory, visual recognition, and verbal fluency) have been described among others by Green et al. [46,47]. While short-term adverse events are well understood, studies covering long periods of time are rare and limited to protocol 30891 of the EORTC [48]. This is a factor that needs to be taken into account when immediate versus delayed endocrine management is considered in men who are known to have conditions, with a very long natural history, such as locally confined PC or a rising PSA after RP or radiotherapy. Considering the potential side effects of ET, obviously has to be individualized when a decision about immediate or delayed treatment is to be taken.

\section{Hormone-resistant Prostate Cancer}

Our knowledge of the mechanisms involved in androgen independence, which is now known as castration-resistant prostate cancer (CRPC), remains incomplete [49-52]. The precise definition of recurrent or relapsed PCa remains controversial and several groups have recently published practical recommendations for defining CRPC. This is based predominantly on the implications of recent findings suggesting that advancing prostate cancer is not uniform 1 year refractory to further hormonal manipulation and that androgens and the progression of disease are frequently dependent on - not independent on - androgen-AR interactions. Paradoxically, CRPC often remains responsive to other hormonal therapies [53-55] in large part due to the intratumoral regeneration of androgens [56,57]. Therefore, after the development of CRPC, patients are often treated with secondary hormonal therapies that further deplete androgen concentrations, or directly bind and inhibit AR [58]. The current palliative treatment options for patients with CRPC can be divided into different groups such as secondary hormonal therapies, chemotherapy agents, vaccine-based immune therapy, bisphosphonates, radiotherapy and novel targets. For patients whose disease progresses after a maximum androgen blockade( $\mathrm{MAB})$, antiandrogen can be discontinued [59] or can be switched to an alternative antiandrogen as showed in several reports [59-61]. High-dose (150 mg daily) bicalutamide as second-line hormonal therapy resulted in $\geq 50 \%$ PSA reduction in $20 \%-45 \%$ of patients $[59,62,63]$. Diethylstilboestrol (DES), a synthetic estrogen, reduces $\geq 50 \%$ the total PSA in $26 \%$ to $66 \%$ of patients with CRPC. However, the thromboembolic toxicity limited is use $[59,64,65]$. Ketoconazol is an antifungal agent that can be given to CRPC patients after antiandrogen withdrawal because it inhibits cytochrome P-450 enzyme-mediated steroidogenesis in testes and adrenal glands and when given at high-dose $(1200 \mathrm{mg} /$ day $)$ or low dose $(600 \mathrm{mg} /$ day) it resulted in $\geq 50 \%$ PSA reduction in $27 \%$ to $63 \%$ and 27 to $46 \%$, of patients, respectively [59]. Abiraterone acetate, a prodrug of abiraterone, is potent and highly selective inhibitor of androgen biosynthesis that blocks cytochrome P450 c17 (CYP 17), a critical enzyme in testosterone synthesis, thereby blocking androgen synthesis by the adrenal glands and testes and within prostate tumor [66-70]. The Cou-AA-301 trial compared abiraterone acetate (1000 mg once daily) plus prednisone versus placebo plus prednisone in patients who had previously received docetaxel. This study randomly assigned 1195 patients and the results exceeded the preplanned criteria, with an overall survival longer in the abiraterone arm (14.8 months versus 10.9 months) $(\mathrm{p}<0.0001)$ and with all secondary end points favoring the treatment group, including time to PSA progression (10.2 versus 6.6 months) $(\mathrm{p}<0.001)$, progression-free survival $(5.6$ months versus 3.6 months $)(\mathrm{p}<0.001)$, and PSA response rate $(29 \%$ versus $6 \%)$ $(p<0.001)[66]$. MDV3100 is an androgen receptor antagonist which prevents nuclear translocation and recruitment of coactivators; it has been shown antitumor activity in men with CRPC after failure of prior hormonal therapy, in phase I/II trial [71,72]. The AFFIRM trial (a phase III trial) compared MDV3100 versus placebo in patients with docetaxelrefractory CRPC [59,73-75], the median survival was 18.4 months for men treated with MDV3100, compared with 13.6 months for men treated with placebo $(\mathrm{p}<0.0001)$. The PREVAIL trial (A safety and efficacy study of oral MDV3100 in chemotherapy-naive patients with progressive metastatic prostate cancer) is still ongoing and recruiting patients. Denosumab is also an effective treatment for patients with 
CRPC and bone metastases. In a phase III study denosumab, a human monoclonal antibody against RANKL, was compared with zoledronic acid for prevention of skeletal-related events. The results showed advantage to denosumab, representing another treatment opportunity for CRPC patients [76]. Docetaxel is the only approved chemotherapy that has been shown to prolong survival among men with metastatic CRPC. The trial TAX 327 compared chemotherapy with docetaxel plus prednisone versus mitoxantrone plus prednisone with a $24 \%$ relative reduction for men with metastatic CRPC and a significant survival benefit $(\mathrm{p}=0.009)$ in the docetaxel arm $[70,77]$. Docetaxel was also effective in pain reduction (35\% versus $22 \%)(\mathrm{p}=0.001)[70,77]$. In SWOG 9916 trial, docetaxel plus estramustine was compared with mitoxantrone plus prednisone and the docetaxel regimen also conferred a significant survival benefit (HR for death $0.80 ; 95 \% \mathrm{CI}=0.67-0.97$ ) and increased median survival (17.5 versus 15.6 months) $(\mathrm{p}=0.02)$ over the mitoxantrone arm $[72,78]$. In the TROPIC trial, a randomized phase III study compared cabazitaxel plus prednisone versus mitoxantrone plus prednisolone, in patients with docetaxel-refractory prostate cancer. The cabazitaxel arm showed an improvement in median PFS ( 2.8 months versus 1.4 months) $(\mathrm{p}<0.0001)$, median OS (15.1 months versus 12.7 months), and lower risk of death (hazard ratio 0.70) $(\mathrm{p}<0.0001)[8,14,65]$. Sipuleucel-T (Provenge, APC8015) is an autologous dendritic cell vaccine. The subsequent IMPACT trial, a phase III, resulted in a 4.1-month improvement in median overall survival and an improvement in the rate of 3 -year survival (31\% versus 23\%) in sipuleucel-T arm, with limited toxicity [15]. GVAX (CGI940/ CG8711) is a cellular vaccine composed of two allogeneic prostate cancer cell lines (LNCaP and PC-3) that is genetically modified to secrete GM-CSF [17]. This vaccine showed clinical benefit with limited toxicity in phase I and II trials $[18,68,69]$. However, the two phase III trials (VITAL-1 and VITAL-2) evaluated GVAX against docetaxel plus prednisone in naive CRPC and both were closed prematurely $[59,71]$. The VITAL-1 study was closed when the unplanned futility analysis revealed a $<30 \%$ chance of meeting its predefined primary endpoint of OS improvement and the VITAL-2 terminated when an interim analysis revealed more deaths in the GVAX arm than in the control [59,70,71,73,79-83]. PROSTVAC-VF is a cancer vaccine consisting of a recombinant vaccinia vector. This vaccine was evaluated in phase I and II trials. The phase I trial showed PSA stabilization in $40 \%$ of patients and limited toxicity and, in the phase II study, patients in the PROSTVAC-VF arm achieved an 8.5-month improvement in median OS (25.1 months versus 16.6 months) and a $44 \%$ reduction in the Prostate Cancer 5 death rate (Hazard ratio $0.56, \mathrm{p}=0.0061$ ) [71,72]. Phase III trial are being planned and other vaccines are under current development [73].

\section{Conclusions}

This systematic review showed that early intervention with hormonal treatments significantly reduces the risk of overall mortality. Whether immediate or deferred hormonal treatment is best for patients who are not suitable for curative local treatment of prostate cancer has been debated since its introduction [2,32]. These advantages of early treatment are, infact, strongly dependent on the stage of the disease. In metastatic disease, the window for delaying hormonal therapy is extremely short, the survival advantages of delaying hormonal therapy could not be shown. Therefore, the consensus is that cases of metastatic disease should be treated by endocrine means to offer the benefit of delay or further progression and temporary suppression of symptoms. In loco-regional disease (T3-4N0-1M0Gx), most trials show an advantage in PC-specific mortality, which in some trials translates into a significant advantage in overall survival. In three good- quality, randomised, controlled trials, i.e. namely VACURG I and II studies [24,25], the MRC trial [26], the early androgen suppression significantly reduced disease progression and complication rates due to progression itself. However, it did not improve cancer-specific survival and provided a relatively small benefit in OS, with an absolute risk reduction of $5.5 \%$ after 10 years [32]. Infact the first studies, which addressed the issue of EET versus DET were three separate studies carried out by the Veterans Administration Co-operative Research Group [24,25] and Byar and Corle [83]. These studies all included arms of various dosages of diethylstilbestrol (DES) and an arm of no treatment. The first study of this series also included castration and castration plus diethylstilbestrol. During the course of a 9-year followup period, virtually all men who progressed with metastastic diseases or to metastatic disease in the control arm were eventually treated endocrinologically. It is for this reason that the VACURG studies are considered to be in fact studies of early versus delayed endocrine management. Since there is no difference in overall survival with respect to the original randomization, one important conclusion of the trials was that ET could be delayed without impairing overall survival. The trials however did suggest a positive effect of early treatment on PC related mortality. This effect was exclusively seen in patients who were treated by means of DES in poorly differentiated cancers. The favorable effect of this treatment on PC progression was completely neutralized by an increase in the cardiovascular death rate in the DES arms, which may have been one of the reasons why survival benefit was not shown. Knowledge about these adverse events and their dose dependence is one of the important results of the VACURG studies. Further to the VACURG studies, there are other randomized trials, which fall into this category. The EORTC 30891 study [30] has produced the same results, namely a small benefit in OS, but no cancer-specific survival benefit. These are EORTC protocol 30846 [28], EORTC 30891, a study which includes locally confined disease and of which the final results have just been reported, protocol 08-88 of the Swiss Oncology Group [32] and the Medical Research Council Prostate Cancer trial in 1997 [26]. All trials show at least modest advantages in PC-specific survival for immediate treatment. This translates into an advantage in overall survival only in the MRC trial. In the MRC trial, significant differences were seen in favor of early treatment with respect to important disease related complications, such as the rate of spinal cord compression, the rate of urethral obstructions, and the rate of extra skeletal metastases. Most of these problems were not encountered in trials that utilized a more frequent follow-up period, in comparison to the yearly checkups in the MRC trial. None of the studies measured quality of life. In conclusion, early intervention with hormonal treatment for patients with LAPC provides important reductions in all-cause mortality, prostate cancer-specific mortality, overall progression, and distant progression compared with deferring their use until standard care has failed to halt the disease. Early introduction of hormone therapy should be offered to men at highest risk of disease progression and cancerrelated death.

\section{References}

1. http://seer.cancer.gov/statfacts/html/prost.html

2. Huggins C, Hodges CV (1941) Studies on prostate cancer. I. The effect of estrogen and of androgen injection on serum phosphatases in metastatic carcinoma of the prostate. Cancer Research 1: 293-297.

3. Huggins C, Stevens RE, Hodges CV (1941) Studies on prostatic cancer II. The effects of castration on advanced carcinoma of the prostate gland. Arch Surg 43: 209-223

4. Geller J, Albert J, Vik A (1988) Advantages of total androgen blockade in the treatment of advanced prostate cancer. Semin Oncol 15: 53-61. 
Citation: Prezioso D, lacono F, Romeo G, Ruffo A, Russo N, et al. (2013) Early vs. Delayed Hormonal Treatment in Locally Advanced or Asymptomatic Metastatic Prostatic Cancer Patient Dilemma: A Review. J Steroids Hormon Sci S5: 001. doi:10.4172/2157-7536.S5-001

5. M Bolla, H Van Poppel, P Van Cangh, K Vekemans (2004) Does post-operative radiotherapy $(\mathrm{P}-\mathrm{RXT})$ after radical prostatectomy $(\mathrm{Px})$ improve progressionfree survival (PFS) in pT3N0 prostate cancer (PC)? (EORTC 22911). Proc Am Soc Clin Oncol 23: 382

6. Grossfeld GD, Latini DM, Lubeck DP, Mehta SS, Carroll PR (2003) Predicting recurrence after radical prostatectomy for patients with high risk prostate cancer. J Urol 169: 157-163.

7. Catton C, Gospodarowicz M, Mui J, Panzarella T, Milosevic M, et al. (2002) Clinical and biochemical outcome of conventional dose radiotherapy for localized prostate cancer. Can J Urol 9: 1444-1452.

8. Gretzer MB, Epstein JI, Pound CR, Walsh PC, Partin AW (2002) Substratification of stage T1c prostate cancer based on the probability of biochemical recurrence. Urology 60: 1034-1039

9. Hull GW, Rabbani F, Abbas F, Wheeler TM, Kattan MW, et al. (2002) Cancer control with radical prostatectomy alone in 1,000 consecutive patients. J Uro 167: 528-534.

10. Pound CR, Partin AW, Eisenberger MA, Chan DW, Pearson JD, et al (1999) Natural history of progression after PSA elevation following radical prostatectomy. JAMA 281: 1591-1597.

11. National Institute for Health \& Clinical excellence (2002) Guidance on Cance Services - Improving Outcomes in Urological Cancers: the Manual, September.

12. Hope RA, Longmore JM, McManus SK, Wood-Allum C (1998) Oxford Handbook of Clinical Medicine. (4th edn), Oxford: Oxford University Press.

13. Penson DF, Litwin MS (2003) The physical burden of prostate cancer. Urol Clin North Am 30: 305-313.

14. Rosenfeld B, Roth AJ, Gandhi S, Penson D (2004) Differences in health-related quality of life of prostate cancer patients based on stage of cancer. Psychooncology 13: 800-807.

15. Lintz K, Moynihan C, Steginga S, Norman A, Eeles R, et al. (2003) Prostate cancer patients' support and psychological care needs: survey from a nonsurgical oncology clinic. Psycho-oncology 12: 769-783.

16. Smith MR (2004) Osteoclast-targeted therapy for prostate cancer. Curr Treat Options Oncol 5: 367 -375.

17. Smith Jr JA, Soloway MS, Young MJ (1999) Complications of advanced prostate cancer. Urology 54: 8-14

18. Ullrich PM, Carson MR, Lutgendorf SK, Williams RD (2003) Cancer fear and mood disturbance after radical prostatectomy: consequences of biochemical evidence of recurrence. J Urol 169: 1449-1452.

19. Petitti DB (2000) Meta-Analysis, Decision Analysis, and Cost-Effectiveness Analysis: Methods for Quantitative Synthesis in Medicine. (2ndedn), Oxford: Oxford University Press.

20. Montreuil B, Bendavid Y, Brophy J (2005) What is so odd about odds? Can J Surg 48: 400-408.

21. Egger M, Davey Smith G, Schneider M, Minder C (1997) Bias in meta-analysis detected by a simple, graphical test. BMJ 315: 629-634.

22. Stats Direct Ltd, 2002. Accessed January 2007.

23. Nesbit RM, Baum WC (1950) Endocrine control of prostatic carcinoma; clinical and statistical survey of 1,818 cases. J Am Med Assoc 143: 1317-1320.

24. (1967) Treatment and survival of patients with cancer of the prostate. Veterans Administration Cooperative Urological Research Group Surg Gynecol Obste 124: 1011-1017.

25. Christensen MM, Aagaard J, Madsen PO (1990) Reasons for delay of endocrine treatment in cancer of the prostate (until symptomatic metastases occur). Prog Clin Biol Res 359: 7-14.

26. (1997) Immediate versus deferred treatment for advanced prostatic cancer: initial results of the Medical Research Council trial. The Medical Research Council Prostate Cancer Working Party Investigators Group. Br J Urol 79: 235

27. Kirk D (2000) Immediate vs. deferred hormone treatment for prostate cancer: how safe is androgen deprivation? BJU Int 86: 220.

28. Schroder FH, Kurth KH, Fosså SD, Hoekstra W, Karthaus PPM, et al. (2004) Early versus delayed endocrine treatment of pN1-3 M0 prostate cancer without local treatment of the primary tumor: results of European Organisation for the Research and Treatment of Cancer 30846-a phase III study. J Urol 172: 923 927.

29. Wirth MP, See WA, McLeod DG, Iversen P, Morris, et al. (2004) Bicalutamide $150 \mathrm{mg}$ in addition to standard care in patients with localized or locally advanced prostate cancer: results from the second analysis of the early prostate cancer program at median followup of 5.4 years. J Urol 172: 1865-1870.

30. Selli C (2006) Re: Immediate or deferred androgen deprivation for patients with prostate cancer not suitable for local treatment with curative intent: european organisation for research and treatment of cancer (EORTC) trial 30891. Eur Urol 50: 384-385.

31. Klotz L (2004) Active surveillance with selective delayed intervention: using natural history to guide treatment in good risk prostate cancer. J Urol 172: S48S50.

32. Thompson IM, Zeidman EJ, Rodriguez FR (1990) Sudden death due to disease flare with luteinizing Hormone-releasing hormone agonist therapy for carcinoma of the prostate. J Urol 144: 1479-1480.

33. Oefelein MG, Feng A, Scolieri MJ, Ricchiutti D, Resnick MI (2000) Reassessment of the definition of castrate levels of testosterone: implications for clinical decision making. Urology 56: 1021-1024.

34. Labrie F, Belanger A, Veilleux R, Lacoste D, Labrie C, et al. (1988) Rationale for maximal androgen withdrawal in the therapy of prostate cancer. Baillieres Clinical Oncology 2: 597-619.

35. Eisenberger MA, Blumenstein BA, Crawford ED, Miller G, McLeod DG, et al (1998) Bilateral orchiectomy with or without Flutamide for metastatic prostate cancer. N Engl J Med 339: 1036-1042.

36. Ellis WJ, Grayhack JT (1963) Sexual function in ageing males after orchiectomy and estrogen therapy. J Urol 89: 895-899.

37. Schroder FH, Collette L, de Reijke TM, Whelan P (2000) Prostate cance treated by anti-androgens: is sexual function preserved? EORTC Genitourinary Group. European Organization for Research and Treatment of Cancer. $\mathrm{Br} J$ Cancer 82: 283-290.

38. Radlmaier A, Neumann F, Bormacher K (1989) Hot flushes: mechanism and prevention. Prog Clin Biol Res 303: 89.

39. Loprinzi CL, Michalak JC, Quella SK, O'Fallon JR, Hatfield AK, et al. (1994) Megestrol acetate for the prevention of hot flashes. N Engl J Med 331: 347-352.

40. Dawson NA, McLeod DG (1995) Dramatic prostate specific antigen decrease in response to

41. discontinuation of megestrol acetate in advanced prostate cancer: expansion of the antiandrogen

42. withdrawal syndrome. J Urol 153: 1946-1947.

43. Daniell HW (1997) Osteoporosis after orchiectomy for prostate cancer. J Uro 157: 439-444.

44. Saad F, Gleason DM, Murray R, Tchekmedyian S, Venner P, et al. (2002) A randomized, placebo-controlled trial of zoledronic acid in patients with hormonerefractory metastatic prostate carcinoma. J Natl Cancer Inst 94: 1458-1468.

45. Smith MR (2003) Changes in body composition during hormonal therapy for prostate cancer. Clin Prostate Cancer 2: 18-21.

46. Yannucci J, Manol J, Garnick M , Bubley G (2005) The effect of androgen deprivation therapy (ADT) on lipid and $\mathrm{Hb}$ parameters. Proceedings of the American Society of Clinical Oncology. May 13-17, Orlando, FL, USA

47. Keating NL, O'Malley AJ, Smith MR (2006) Diabetes and cardiovascula disease during androgen deprivation therapy for prostate cancer. J Clin Oncol 24: 4448-4456

48. Green HJ, Pakenham KI, Headley BC, Yaxley J, Nicol DL, et al. (2002) Altered cognitive function in men treated for prostate cancer with luteinizing hormonereleasing hormone analogues and Cyproterone acetate: a randomized controlled trial. BJU Int 90: 427-432.

49. Green HJ, Pakenham KI, Headley BC, Yaxley J, Nicol DL, et al. (2004) Quality of life compared during pharmacological treatments and clinical monitoring fo non-localised prostate cancer: a randomised controlled trial. BJU Int 93: 975 979. 
Citation: Prezioso D, lacono F, Romeo G, Ruffo A, Russo N, et al. (2013) Early vs. Delayed Hormonal Treatment in Locally Advanced or Asymptomatic Metastatic Prostatic Cancer Patient Dilemma: A Review. J Steroids Hormon Sci S5: 001. doi:10.4172/2157-7536.S5-001

Page 8 of 8

50. Studer UE, Hauri D, Hanselmann S, Chollet D, Leisinger HJ, et al. (2004) Immediate versus deferred hormonal treatment for patients with prostate cance who are not suitable for curative local treatment: results of the randomized trial SAKK 08/88. J Clin Oncol 22:4109-4118.

51. Isaacs JT, Coffey DS (1981) Adaptation versus selection as the mechanism responsible for the relapse of prostatic cancer to androgen ablation therapy as studied in the Dunning R-3327-H adenocarcinoma. Cancer Res 41: 5070-5075.

52. Horoszewicz JS, Leong SS, Kawinski E, Karr JP, Rosenthal H, et al. (1983) LNCaP model of human prostatic carcinoma. Cancer Res 43: 1809-1818.

53. Taplin ME, Bubley GJ, Shuster TD, Frantz ME, Spooner AE, et al. (1995) Mutation of the androgen-receptor gene in metastatic androgen-independent prostate cancer. N Engl J Med 332: 1393-1398.

54. Visakorpi T, Hyytinen E, Kovisto P (995) Amplification of the androgen recepto gene is common in recurrent prostate cancer from patients treated with androgen withdrawal. J Urol 153: 379A.

55. Scher HI, Sawyers CL (2005) Biology of progressive, castration-resistant prostate cancer: directed therapies targeting the androgen-receptor signaling axis. J Clin Oncol 23: 8253-8261.

56. McPhaul MJ (2008) Mechanisms of prostate cancer progression to androgen independence. Best Practice \& Research. Clinical Endocrinology \& Metabolism 22: $373-388$

57. Sharifi $N$ (2010) New agents and strategies for the hormonal treatment of castration-resistant prostate cancer. Expert Opin Investig Drugs 19: 837-846.

58. Titus MA, Schell MJ, Lih FB, Tomer KB, Mohler JL (2005) Testosterone and dihydrotestosterone tissue levels in recurrent prostate cancer. Clin Cancer Res 11: 4653-4657.

59. Montgomery RB, Mostaghel EA, Vessella R, Hess DL, Kalhorn TF, et al (2008) Maintenance of intratumoral androgens in metastatic prostate cancer: a mechanism for castration-resistant tumor growth. Cancer Res 68: 4447-4454.

60. Ryan CJ, Small EJ (2005) Secondary hormonal manipulations in prostate cancer. Current Oncology Reports 7: 228-233.

61. Kim SJ, Kim SI (2011) Current treatment strategies for castration-resistan prostate cancer. Korean J Urol 52: 157-165.

62. Suzuki H, Okihara K, Miyake H, Fujisawa M, Miyoshi S, et al. (2008) Alternative nonsteroidal antiandrogen therapy for advanced prostate cancer that relapsed after initial maximum androgen blockade. J Urol 180: 921-927.

63. Kassouf W, Tanguay S, Aprikian AG (2003) Nilutamide as second line hormone therapy for prostate cancer after androgen ablation fails. J Urol 169: 1742 1744

64. Joyce R, Fenton MA, Rode P, Constantine M, Gaynes L, et al. (1998) High dose bicalutamide for androgen independent prostate cancer: effect of prior hormonal therapy. J Urol 159: 149-153.

65. Kucuk O, Fisher E, Moinpour CM, Coleman D, Hussain MH, et al. (2001) Phase II trial of bicalutamide in patients with advanced prostate cancer in whom conventional hormonal therapy failed: a Southwest Oncology Group study (SWOG 9235). Urology 58: 53-58.

66. Sonpavde G, Hutson TE, Berry WR (2006) Hormone refractory prostate cancer: management and advances. Cancer Treat Rev 32: 90-100.

67. Smith DC, Redman BG, Flaherty LE, Li L, Strawderman M, et al. (1998) A Phase II trial of oral diethylstilbesterol as a second-line hormonal agent in advanced prostate cancer. Urology 52: 257-260.

68. de Bono JS, Logothetis CJ, Molina A, Fizazi K, North S, et al. (2011) Abiraterone and increased survival in metastatic prostate cancer. N Engl J Med 364: 19952005

69. Potter GA, Barrie SE, Jarman M, Rowlands MG (1995) Novel steroida inhibitors of human cytochrome P45017 alpha (17alpha-hydroxylase-C17,20 lyase): potential agents for the treatment of prostatic cancer. J Med Chem 38 : 2463-2471.

70. Attard G, Belldegrun AS, de Bono JS (2005) Selective blockade of androgenic steroid synthesis by novel lyase inhibitors as a therapeutic strategy for treating metastatic prostate cancer. BJU Int 96: 1241-1246.

71. Barrie SE, Haynes BP, Potter GA, Chan FC, Goddard PM, et al. (1997) Biochemistry and pharmacokinetics of potent non-steroidal cytochrome P450(17alpha) inhibitors. J of Steroid Biochem Mol Biol 60: 347-351.

72. Jarman M, Barrie SE, Llera JM (1998) The 16,17-double bond is needed for irreversible inhibition of human cytochrome $\mathrm{P} 45017 \alpha$ by abiraterone (17-(3-Pyridyl)androsta-5,16-dien-3ß-ol) and related steroidal inhibitors. J Med Chem 41: 5375-5381.

73. Vishnu P, Tan WW (2010) Update on options for treatment of metastatic castration-resistant prostate cancer. Onco Targets Ther 3: 39-51.

74. Sartor AO (2011) Progression of metastatic castrate-resistant prostate cancer: impact of therapeutic intervention in the post-docetaxel space. J Hemato Oncol 4:18.

75. Bianchini D, Zivi A, Sandhu S, de Bono JS (2010) Horizon scanning for nove therapeutics for the treatment of prostate cancer. Ann Oncol 21: vii43-vii55.

76. Scher HI, Beer TM, Higano CS, Anand A, Taplin ME, et al. (2010) Antitumou activity of MDV3100 in castration-resistant prostate cancer: a phase 1-2 study. Lancet 375: 1437-1446.

77. Zarour L, Alumkal J (2010) Emerging therapies in castrate-resistant prostate cancer. Curr Urol Rep 11: 152-158.

78. Fizazi K, Carducci M, Smith M, Damião R, Brown J, et al. (2011) Denosumab versus zoledronic acid for treatment of bone metastases in men with castrationresistant prostate cancer: a randomised, double-blind study. The Lancet 377 813-822.

79. Crawford ED, Eisenberger MA, McLeod DG, Spaulding JT, Benson R, et al. (1989) A controlled trial of leuprolide with and without flutamide in prostatic carcinoma. N Engl J Med 321: 419-424.

80. Petrylak DP, Tangen CM, Hussain MHA, Lara Jr. PN, Jones JA, et al. (2004) Docetaxel and estramustine compared with mitoxantrone and prednisone for advanced refractory prostate cancer. N Engl J Med 351: 1513-1520.

81. Kantoff PW, Schuetz TJ, Blumenstein BA, Glode LM, Bilhartz DL, et al. (2010) Overall survival analysis of a phase II randomized controlled trial of a Poxviralbased PSA-targeted immunotherapy in metastatic castration resistant prostate cancer. Journal of Clinical Oncology 28: 1099-1105.

82. Sonpavde G, Slawin KM, Spencer DM, Levitt JM (2010) Emerging vaccine therapy approaches for prostate cancer. Rev Urol 12: 25-34.

83. Carducci MA, Jimeno A (2006) Targeting bone metastasis in prostate cancer with endothelin receptor antagonist. Clini Cancer Res 12: 6296s.

84. Wilt T, Nair B, MacDonald R, Rutks I (2001) Early versus deferred androgen suppression in the treatment of advaced prostatic cancer. Cochrane database Syst Rev.

85. Byar DP, Corle DK (1988) Hormone therapy for prostate cancer: results of the Veterans Administration Cooperative Urological Research Group studies. NCI Monographs 7: 165-170.
This article was originally published in a special issue, Hormonal Therapy handled by Editors. Dr. Ratna K Vadlamudi, University of Texas San Antonio, TX, USA; Dr. Baharudin Bin Abdullah, School of Medical Sciences, Health Campus USM, Malaysia 